\title{
Escola do Campo: Análise da execução do recurso do PDDE
}

\section{Escola do campo: Analysis of the execution of the PDDE resource}

\author{
Francisco Xavier de Mendonça 1
}

\begin{abstract}
RESUMO
Esta pesquisa faz uma abordagem sobre as dificuldades de uma escola do campo, no que se refere à infraestrutura, acessibilidade, recebimento de recurso público e que medidas são adotadas para a execução desse recurso. O estudo foi realizado na Escola Municipal de Educação Infantil e Fundamental Juracy Batista de Jesus, localizada no Assentamento Massangana I, Município de Cruz do Espírito Santo - PB. O levantamento de dados foi obtido com aplicação de questionários com diretor escolar, presidente e conselheiros do conselho escolar. Tendo como nosso principal objetivo analisar a gestão dos recursos da escola do campo e os entraves que dificultam a sua gestão, além de identificar os métodos utilizados pelo conselho escolar ao receber os recursos do FNDE, verificando se existe transparência com relação ao recurso recebido que favoreça uma gestão democrática. Mediante os dados analisados percebemos que a referida escola, realiza reuniões com o conselho para definir necessidades e prioridades no tocante às compras de materiais e execução de serviço como o recurso do PDDE, no entanto, não existia uma lei que normalizasse tal ação no município, por essa razão será sugerido ao poder público municipal, uma lei que legalize o orçamento democrático das escolas municipais.
\end{abstract}

Palavras-chave: Escola do campo; Recurso do PDDE; Transparência.

\begin{abstract}
This research approaches the difficulties of a rural school, with regard to infrastructure, accessibility, receipt of public resources and what measures are adopted to implement this resource. The study was carried out at the Juracy Batista de Jesus Municipal School of Early Childhood Education, located in the Massangana I Settlement, Cruz do Espírito Santo - PB. The data collection was obtained with the application of questionnaires with the school director, president and counselors of the school council. Having as our main objective to analyze the management of rural school resources and the obstacles that make their management difficult, in addition to identifying the methods used by the school council when receiving FNDE resources, verifying if there is transparency regarding the received resource that favors democratic management. Through the analyzed data, we realized that the aforementioned school holds meetings with the council to define needs and priorities regarding the purchase of materials and service execution as a resource of the PDDE, however, there was no law that normalized such action in the municipality, for this reason, a law that legalizes the democratic budget of municipal schools will be suggested to the municipal government.
\end{abstract}

Keywords: Rural school; PDDE recurse; Transparency.

\footnotetext{
${ }^{1}$ Christian Business School

* E-mail: b.m_prof@hotmail.com
} 


\section{INTRODUÇÃO}

A população do campo, apesar de contribuir com o progresso da nação, não recebeu a atenção que merecia, sobretudo, no que diz respeito ao direito de acesso à educação. Essa situação só começa a ser modificada a partir da década de 1930, quando começa a emergir no cenário brasileiro, o sistema de políticas públicas de educação, em virtude dos esforços de pensadores da educação brasileira, que entusiasmados pelos ideais de uma educação para todos, começam a reivindicar melhorias para a educação, um exemplo é o Manifesto dos Pioneiros da Educação Nova, que conforme Henriques.

O Manifesto buscava diagnosticar e sugerir rumos às políticas públicas de
educação e preconizava a organização de uma escola democrática, que
proporcionasse as mesmas oportunidades para todos e que, sobre a base de uma
cultura geral comum, possibilitasse especializações para as atividades de
preferência intelectual (humanidades e ciências) ou de preponderância anual e
mecânica (cursos de caráter técnico) agrupadas em: extração de matérias-
primas - agricultura, minas e pesca; elaboração de matérias-primas - indústria;
distribuição de produtos elaborados - transportes e comércio. Nessa proposta,
as demandas do campo e da cidade eram igualmente consideradas e
contempladas (HENRIQUES et al, 2007 p.10)..

Nos estados do Brasil havia crescimento do número de escolas seguido de uma melhoria em sua estruturação técnica e administrativa, mas a população rural continuava a ser líder em número de analfabetos. Nesse contexto, pensar a educação do campo é refletir sobre políticas e práticas que ajudem a minimizar os problemas que os sujeitos das áreas rurais enfrentam cotidianamente. Assim, a educação do/no campo deve priorizar uma educação com equidade social, transformadora, ou seja, voltada a realidade dos indivíduos do campo, os quais estão ficando à margem dos direitos sociais, faltando-lhes oportunidades para melhorar a qualidade de vida no campo.

Desta feita, a finalidade desta pesquisa é analisar as dificuldades que as escolas do campo enfrentam para oferecer uma educação de qualidade para os filhos do homem do campo, no que se refere à infraestrutura, acessibilidade, recebimentos de recursos oriundos do Fundo Nacional de Desenvolvimento da Educação- FNDE, e que medidas são adotadas para recebê-los, verificando se os recursos são suficientes para atender a demanda do campo e as principais dificuldades para sua execução.

Para fins de estudo, iniciamos com uma visão histórica da origem da educação rural e os aspectos econômicos, apresentando como surgiu e evoluiu até os dias de hoje, além das contribuições dos movimentos sociais para várias conquistas, que amenizaram a distância entre a educação urbana e rural, mas, que posteriormente se tornaria a educação do campo, a luz das contribuições da Constituição Federal de 1934, sobretudo, com o Manifesto da Escola Nova, bem 
como a Lei de Diretrizes e Base da Educação (LDB), a qual contempla a gestão democrática do ensino público e autonomia financeira para administração das escolas públicas, com criação dos conselhos escolares e com a elaboração do Projeto Político Pedagógico (PPP), estas conquistas foram bastante significativas para melhorar a estrutura das escolas do campo, mesmo reconhecendo não ser ainda a ideal.

Nosso principal objetivo foi realizar uma pesquisa em uma escola do campo através do estudo, fazer uma coleta de dados dos entraves que dificulta a gestão do recurso e identificar os métodos utilizados pelos conselhos escolares ao receber os recursos do FNDE, verificando se existe ações que favoreçam uma gestão democrática. Diante dos problemas, percebemos que não existem prioridades de políticas públicas para atender essas necessidades e como também em alguns casos há a falta de transparência na execução de recurso e elaboração de um plano com base nas necessidades e prioridades da assembleia que contemple as reais necessidades das escolas.

\section{METODOLOGIA}

O presente artigo trata-se de uma pesquisa de campo com elaboração e utilização de questionário de entrevista com presidente de conselho escolar e membros e o gestor escolar. Com leitura e análise de atas do Conselho Escolar que discorrem sobre o recurso do Programa Dinheiro Direto na Escola-PDDE, com base nos procedimentos adotados para aquisições de materiais e prestação de serviços e, por conseguinte, as prestações de contas com a comunidade escolar e com a Secretaria de Educação.

A pesquisa bibliográfica tem como referência, a origem da educação do campo e as perspectivas nos dias atuais e tabulação dos questionários de entrevistas com o gestor escolar e o presidente do conselho, representantes dos professores, alunos, funcionários e pais de alunos. Este artigo teve por finalidade analisar as dificuldades de uma escola do campo em relação às insuficiências de recursos para o seu funcionamento diário. Sabemos que são vários os obstáculos para manter um bom desempenho educacional durante o ano. Mas um bom planejamento se faz necessário para amenizar os entraves que são enfrentados pelas instituições do campo com o pouco recurso que recebem para a manutenção anual.

\section{FUNDAMENTAÇÃO TEÓRICA}

\subsection{Educação rural, a educação do campo}

A perspectiva da educação rural teve início pela base cultural do trabalho escravo e os latifúndios, sobre o controle das oligarquias política e econômica do nosso país. Embora tendo início ainda no século XIX, foi na década de 30 do século XX que surgiu referência à educação 
rural com visão voltada para a agro exportação, pensando numa inovação agrícola, seguindo modelo de empresa de outros países.

O exemplo de educação rural no Brasil surge objetivando atender exigências de organismos internacionais, não propriamente uma política voltada a atender as necessidades da população rural, pois o mesmo estava voltado para a constituição da força de trabalho, cada vez mais moderno, com a utilização de máquinas que pudessem aumentar o plantio das lavouras e consequentemente, a produção das propriedades rurais, favorecendo o agronegócio.

O que temos, então, a partir da década de 1950, é a gestão de um discurso urbanizador que enfatiza a fusão entre os dois espaços, urbano e rural, por acreditar que o desenvolvimento industrial, em curso no Brasil, faria desaparecer dentro de algumas décadas a sociedade rural, ou seja, "o campo é uma divisão sociocultural a ser superada, e não mantida" (Moreira apud Abraão, 1989).

A escola rural nesse período, não apresentava particularidade que fosse favorável à realidade de aprendizagem de conhecimentos de saberes por eles constituídos, não levavam em consideração os valores culturais necessários à formação da sociedade.

As políticas públicas criadas para a educação da população rural apresentavam desempenho insuficiente do qual resultava uma total falta de prioridade do país com a Educação Rural. O índice de analfabetismo no Brasil nas áreas rurais é três vezes mais elevado do que as taxas urbanas. Conforme o índice de analfabetismo urbano era de 7,3\% em 2010, no campo, apresenta uma taxa de 23,3\%, de acordo com o Censo 2010 do IBGE.

O golpe de 1964 reforçou cada vez mais a educação nas áreas urbanas, impossibilitando que a participação de movimentos populares que lutavam pela educação, e várias lideranças fossem perseguidas e exiladas pela imposição do regime. Mas o analfabetismo era o grande gargalo para a classe dominante do Brasil, que tinha com pretensão, uma progressão do país no cenário internacional. Por essa razão, nesse período, foram organizadas várias campanhas de combate ao analfabetismo, com a finalidade de projetar o país ao desenvolvimento social e econômico.

Mesmo com as políticas públicas no sentido de universalizar o Ensino Fundamental em nosso país, ainda persiste uma desigualdade entre a escola urbana e a do campo, de modo que são diversos os obstáculos que crianças e jovens enfrentam para concluir o Ensino Fundamental e chegar ao Ensino Médio, o número de matrículas das escolas do campo são maiores na primeira fase do ensino fundamental até o $5^{\circ}$ ano, pois para continuar a estudar, o aluno necessita se deslocar para a cidade, no intuito de realizara segunda fase do ensino fundamental e ensino médio.

A diminuição da oferta de matriculas pode ser percebida na distribuição por ciclo na etapa básica de educação, que conforme estudo da desigualdade ao direito realizado em 2009: as exigências de políticas afirmativas para promoção da equidade promocional no campo, para a 
entidade vinculada ao Conselho de Desenvolvimento Econômico Social, apresentam dados que para duas crianças nos anos inicias do ensino fundamental, uma apenas chega aos anos finais.

E para seis vagas nos anos finais, apenas uma consegue chegar ao Ensino Médio. Nas escolas da zona urbana a base das matriculas são de quatro vagas nas séries iniciais, três nas series finais e duas no Ensino Médio. Os obstáculos para continuar estudando são grandes quando se avalia a escolaridade dos jovens. A população que vive na zona urbana, entre 25 a 34 anos, tem Ensino Médio ou Superior. No campo, esse percentual é de 17\%, situação que necessita ser bem avaliada, ensejando em busca de políticas públicas que possa rever essa distorção.

Para Mônica Molina, professora de pós-graduação em educação da Universidade de Brasília uma das responsáveis pelo estudo do observatório da equidade, há falta de uma prioridade dos órgãos governamentais em políticas públicas para diminuir essa nítida desigualdade.

\subsection{Surgimento de leis que garantiam uma educação do campo}

As dificuldades na educação sempre foram grandes, principalmente para atender a população na zona rural, foi a partir de 1932, que aconteceu o Manifesto dos pioneiros da Escola nova, e as contribuição das constituições de 1934, 1937 e 1946 as Leis Orgânicas do Ensino Agrícola (LOEA) e os Relatório da Campanha Nacional da Educação Rural. Essas conquistas favoreciam uma melhor condição de vida ao homem do campo.

O Manifesto dos Pioneiros da Escola Nova de 1932 foi um marco na história da Educação do campo, várias propostas reivindicadas por eles ainda perduram nos dias de hoje, como a gratuidade e obrigatoriedade da educação escolar, organização de plano e diretrizes curriculares nacionais entre outros, que possibilitou a diminuição das desigualdades entre a educação do campo e da cidade. A constituição de 1934, em seu texto, assegura a educação rural através de financiamento.

\footnotetext{
A União, os Estados e os Municípios, aplicarão nunca menos dez por cento, o Distrito Federal, nunca menos de vinte por cento da renda resultante dos impostos, na manutenção e no desenvolvimento dos sistemas educativos. § "Para a realização do ensino nas zonas rurais, a União reservará, no mínimo, vinte por cento das cotas destinadas à educação no respectivo orçamento anual.” (ART. 156, parágrafo único).
}

Com essa iniciativa, o governo federal dar início a uma política que beneficia o homem do campo, e também uma medida de evitar o êxodo rural, até então, as principais políticas de educação estavam voltadas para população urbana. A constituição de 1937, faz atribuição à educação de profissionais, medidas estas que ficariam a cargo dos sindicatos e empresas urbanas e rurais, além de formação técnica profissionais de funcionários e seus filhos. Conforme consta neste artigo: 
Art.129(...) é dever das indústrias e dos sindicatos econômicos criar, na esfera de suas especificidades, escolas de aprendizes, destinadas aos filhos de seus operários ou de seus associados. A Lei regulará o cumprimento desse dever e os poderes que caberão ao Estado sobre essas escolas, bem como os auxílios, facilidades e subsídios a lhe serem concedidos pelo poder público

A constituição de 1946, mantém o texto da educação como direito assegurado da sociedade civil e das empresas com ensino gratuito primário rural, de acordo com o texto a seguir

Arte. 168. A educação é direito de todo e será dada no lar e na escola. Deve inspirar-se nos princípios de liberdade e nos ideais de solidariedade humana.

Inciso III - as empresas industriais, comerciais e agrícolas, em que trabalhavam mais de cem pessoas, são obrigadas a manter ensino primário gratuito para seus servidores e seus filhos

Esta lei possibilitou os primeiros avanços da educação destinada ao homem do campo, formando uma perspectiva de futuro para seus filhos, no período a população que carecia de informações e conhecimentos, imaginava que o ensino oferecido por estas empresas, era um favor que os empresários estavam oferecendo aos seus filhos.

É preciso assegurar aos filhos dos camponeses uma escola de qualidade, que possa the possibilitar uma esperança de viver no campo com perspectiva de futuro, e que é possível permanecer no campo de forma digna, trabalhando a agricultura familiar, conforme dados

\begin{tabular}{|l|l|}
\hline \multicolumn{1}{|c|}{ Agricultura familiar } & \multicolumn{1}{c|}{ Agronegócio } \\
\hline $14 \%$ do crédito & $86 \%$ do crédito \\
\hline $24 \%$ das terras & $76 \%$ das terras \\
\hline $38 \%$ da produção global & $62 \%$ da produção global \\
\hline $70 \%$ das comidas & $30 \%$ das comidas \\
\hline $74 \%$ da mão de obras ocupada & $26 \%$ da mão de obra ocupada \\
\hline
\end{tabular}

Fonte: Censo Agropecuário: 2006.

Os dados apresentados com base no censo agropecuário 2006 mostram claramente a falta de prioridade em detrimento ao homem do campo, e o favorecimento assustador ao agronegócio, mas ao analisar os dados nos leva acreditar que a agricultura familiar é uma solução para combater a crise que o sistema capitalista enfrenta na atualidade, pois o que mais preocupa as futuras gerações é a produção de alimentos e mão de obra, e o pequeno agricultor com apenas $14 \%$ do crédito, supera nesses dois itens, o agronegócio com $86 \%$ do crédito. Não podemos esquecer que o modelo adotado pelo agronegócio é um grande concentrador de renda, e foi responsável por diversos desequilíbrios ambientais, como também, a marginalização do trabalhador do campo. 
Os movimentos sociais têm um papel fundamental na luta para superar os diversos problemas que assolam o camponês, como a reforma agrária, uma política voltada para o aumento do crédito, assistências técnicas, saúde e educação, no sentido de vencer as dificuldades e garantir uma vida digna ao homem do campo.

A partir da década de 90, surgiram os programas destinados à agricultura familiar, isso foi devido às lutas dos movimentos sociais, e são: PRONAF, seguro da agricultura familiar, Programa de aquisição de alimento, Programa de garantia de preço para a agricultura familiar PGPAF, Programa Nacional de Alimentação Escolar (PNAE), Programa Nacional de Biodiesel.

Podemos observar que através da luta pelos seus direitos, o homem do campo tem conseguido algumas conquistas, outro desafio que os mesmos enfrentam e que os programas de crédito exigem projetos bem elaborados, e uma boa parte dos camponeses não sabem ler e escrever para realizarem a elaboração dos projetos e nem contam com assistências técnicas, as agências bancárias não têm metas estabelecidas para atender os pequenos produtores. Infelizmente o nosso país ainda tem base no modelo adotado pelos antigos colonizadores portugueses com o cultivo da terra voltado para exportação

Toda a estrutura de nossa sociedade colonial teve base fora dos meios urbanos. Se não foi a rigor uma civilização agrícola o que os portugueses instauram no Brasil, foi, sem dúvida, uma civilização de raízes rurais. É efetivamente nas propriedades rústicas que toda a vida da colônia se concentrava durante os séculos iniciais da ocupação europeia: as cidades são virtualmente, se não de fato, simples dependência delas. Com pouco exagero pode-se dizer que tal situação não se modificou essencialmente até a abolição. (HOLANDA, 1995, p.41).

A educação durante o período colonial entre 1500 a 1822 que coincide com independência do Brasil, era ministrada pelos jesuítas, que tinham como base, o ensino religioso católico, para atender aos índios e à elite. Esta educação estava voltada para a catequese na qual se resumia em aprender a ler e escrever e os ensinamentos da religião católica. Esta metodologia foi adotada no período entre 1549 a 1759, quando foram expulsos pelo Marquês de Pombal, que alegava que o ensino dos jesuítas representava uma ameaça para metrópole.

Após a expulsão dos jesuítas a colônia necessita de implantar outro modelo de educação e foi adotado o estilo de aulas régias, mas não tinha uma clara definição dos objetivos educacionais e com poucas eficiências.

A escola do campo sempre necessitou uma atenção especial por parte dos governantes, geralmente a maioria dos recursos sempre teve como prioridade as escolas urbanas, esta política discriminatória contribui muito para o aumento da taxa de analfabetismo entre o trabalhador do campo. A LDB Lei $\mathrm{n}^{\circ}$ 9394/96 em seus arts. $3^{\circ} .23,28$ e 61, regulamenta o ensino escolar do campo, esta foi uma conquista muito importante porque o homem do campo consegue assegurar através de uma lei no art. 28 que garante a educação básica para população rural, assim nos incisos define: 
I- Conteúdos curriculares e metodologias apropriadas às reais necessidades e interesses dos alunos da zona rural;

II- Organização escolar própria, incluindo adequação do calendário escolar às fases do ciclo agrícola e às condições climáticas;

III- Adequação à natureza do trabalho do trabalho da zona rural.

A partir dessas conquistas surgia a necessidade de um plano de ensino que contemplasse as escolas do campo, no qual fosse elaborado de maneira participativa e democrática priorizando a realidade de cada escola na localidade que está inserida. $\mathrm{O}$ artigo $4^{\circ}$ da Resolução 01/2002 define como deve ser o Projeto Político Pedagógico das escolas do campo:

O projeto institucional das escolas do campo, expressão do trabalho compartilhado de todos os setores comprometidos com a universalização da educação escolar com a qualidade social, constituir-se-á num espaço público de investigação e articulação de experiências e estudos direcionados para o mundo do trabalho, bem como para o desenvolvimento social, economicamente justo e ecologicamente sustentável. (BRASIL, 2002)

Os movimentos sociais têm grande importância nas lutas e conquistas em prol da educação do campo e com base neste princípio foi realizada em 1998, na cidade de Luziânia GO, a I Conferência Nacional por uma educação do campo "por uma Política Pública de Educação do Campo", promovida pelo MST (Movimento sem Terra) UNICEF, UNESCO, CNBB e UnB. Este espaço motivou um debate bastante significativo para a mobilização popular, e foi levado em consideração os diferentes povos do campo na forma de produção: ribeirinhos, pesqueiros, extrativistas, agricultores, trabalhadores etc. de variados grupos éticos e raciais: os indígenas e os quilombolas.

Em nosso país o trabalhador do campo tem uma identidade cultural originária do seu mundo rural, diferente daqueles que vive na cidade, assumindo em seu cotidiano um ritmo próprio de organizar sua vida e a base familiar bem peculiar à sua realidade, longe dos costumes da cidade.

"A educação do homem seria um processo mediante o qual o homem desabrocha todas as suas potencialidades". (GADOTTI. 2001. p.17). Através da educação o homem desenvolve de maneira geral seu talento, seu modo de agir, em busca de novos conhecimentos e aprimora cada vez mais, a convivência em sociedade, aprendendo a ouvir para falar com sabedoria e refletir em busca de melhor maneira de resolver as mais difíceis tarefas que a vida possa oferecer.

Esta I conferência foi o espaço que o trabalhador do campo estava necessitando para denunciar os mais variados descasos com a educação do campo, números insuficientes de escolas para atender a todas as crianças e jovens; a precariedade na infraestrutura das escolas, ausência de uma política de valorização do magistério; falta de apoio nas renovações pedagógicas; como também o financiamento; um currículo que não atende à realidade do homem do campo; docentes sem a qualificação necessária; elevados índices de analfabetismo; jovens fora da realidade que 
propõe a educação do campo, certa perda da identidade, no qual foi defendido um projeto de educação que motive os jovens a permanecer no campo.

Destas reinvindicações na I Conferência Nacional, fruto de uma conquista resultante das instituições participantes e dos trabalhadores e trabalhadoras do campo, foram aprovadas as Diretrizes Operacionais para a Educação Básica nas Escolas do Campo" (Parecer n 36/2001 e Resolução 1/2002 do Conselho Nacional de Educação).

As lutas dos movimentos sociais têm sido primordiais para várias conquistas obtidas até o momento, isto possibilitou - com que essa pressão que governos municipais, estaduais e federais estão fazendo - a inclusão de uma agenda de prioridade para a educação do campo. Estas conferências foram resultado das lutas sociais referenciadas na Constituição de 1988, em seu artigo 2006, referendado no artigo $3^{\circ}$ da LDB (leis de Diretrizes e Bases da Educação Nacional), Lei no 9.394/96 que contempla a gestão democrática do ensino público na forma desta lei e da legislação do sistema de ensino inciso VIII do artigo $3^{\circ}$.

Tem como objetivo a construção de um processo de gestão democrática, que possibilite o exercício da cidadania de forma independente, que constitua um espaço de construção coletiva dentro dos conselhos escolares, com pensamentos críticos e combate à hierarquia. Diante disso, se faz necessário a elaboração de um Projeto Político Pedagógico que retrate a realidade nacional e local, e ainda, que seja realizada uma avaliação contínua com toda a comunidade escolar (estudantes, pais, professores, funcionários, gestão, sendo assim constituída por entidade escolar e a sociedade civil).

Uma ação intencional, com um sentido explícito, como um compromisso definido coletivamente. Por isso, todo projeto político pedagógico da escola é, também, um projeto político por estar intimamente articulado ao compromisso sócio-político com os interesses reais e coletivos da população majoritária. É político, no sentido de compromisso com afirmação do cidadão para um tipo de sociedade. A dimensão política se cumpre na medida em que ele se realiza enquanto prática pedagógica. (Saviani 1993, p.93)

Para que a gestão democrática possa acontecer se faz necessário que vários atores sociais estejam envolvidos, as secretarias de Educação Municipal e Estadual têm um papel fundamental em orientar a gestão, oferecendo subsídio com formação e apoio técnico para que seja efetivada a elaboração de maneira democrática, com acompanhamento das metas propostas e avaliadas, visando uma educação de boa qualidade.

Na Paraíba, através do Comitê Estadual de Educação do Campo, foi realizado no dia 09 e 10 de outubro de 2013, um Seminário Regional de Educação no Campo (Serec/PB), no município de Sapé. Este seminário foi o nono de uma série de 14, realizado pelo Comitê Estadual de Educação do Campo, em parceria com a Secretaria de Estado da Educação (SEE), por meio da Gerência Operacional de Integração. Que após os debates, professores da Universidade Federal da Paraíba (UFPB) e líderes de movimentos sociais e professores da rede estadual e municipal do vale do Paraíba e litoral, foi elaborada uma carta compromisso, endereçada aos gestores dos 
municípios que participaram dos seminários, em busca de políticas públicas que valorizem a realidade da educação do campo e suas diversidades.

Uma escola autônoma com gestão participativa tem base no artigo 17 da LDB, que afirma:

“Os sistemas de ensino assegurarão às unidades escolares públicas de educação básica que os integram progressivos graus de autonomia pedagógica e administrativa e de gestão financeira, observadas as normas gerais de direito financeiro público".

A LDB em seu artigo 14 afirma:

Os sistemas de ensino definirão as normas da gestão democrática do ensino público na educação básica de acordo com as suas peculiaridades, conforme os seguintes princípios:

I - Participação dos profissionais da educação na elaboração do projeto pedagógico da escola;

II - Participação das comunidades escolar e local em conselhos escolares ou equivalentes.

O artigo 17 da LDB, assegura a autonomia pedagógica para o ensino público na educação básica, como também, a administração financeira dos recursos proveniente do FNDE e Secretarias Estaduais ou Municipais, e que esta execução de recursos seja realizada de forma democrática, envolvendo toda a comunidade escolar. O artigo 14, faz referência à elaboração do PPP (Projeto Político Pedagógico), elemento fundamental da base curricular das escolas e a importância dos conselhos escolares, para administrar a parte financeira e colaborar com todos os assuntos pertinentes a comunidade escolar.

$\mathrm{Na}$ dimensão pedagógica reside a possibilidade da efetivação da intencionalidade da escola, que é a formação do cidadão participativo, responsável, compromissado, crítico e criativo. Pedagógico, no sentido de definir as ações educativas e as características necessárias às escolas de cumprirem seus propósitos e as intencionalidade. (Veiga 1996, p.12)

Segundo Freire, a palavra conscientização tem uma profundidade em seu significado, para quem acredita na educação, como prática da liberdade, é um ato de conhecimento, uma aproximação crítica da realidade. A conscientização não pode existir separada das "práxis", ou melhor dizer, sem ação - reflexão.

\subsection{Funções dos conselhos escolares}

O conselho escolar é um órgão composto por elementos da comunidade escolar e tem como objetivo tratar sobre todas as atribuições concernentes aos estabelecimentos educacionais, no que se refere às ações político-pedagógicas como também financeira. São atribuições dos conselhos, observar as realizações propostas pela escola. Eles representam não apenas a comunidade escolar, com também, a comunidade onde a escola está inserida, definindo ações que são de sua responsabilidade, uma de suas principais atribuições é a abertura para o diálogo, tornando a escola, um espaço de decisões democráticas. 
Conselho Escolar é o órgão colegiado, na estrutura da escola, composto pelo diretor e por representantes dos professores, demais funcionários, pais ou responsáveis, estudantes e comunidade local (se for o caso), que tem por atribuição decidir sobre questões pedagógicas, administrativas e financeiras, no âmbito escolar. Em contrapartida, Unidade Executora é uma entidade privada sem fins lucrativos, representativa das escolas públicas, integrada por membros da comunidade escolar responsável pela formalização dos procedimentos necessários ao recebimento dos repasses de recursos financeiros destinados às escolas, bem como pela execução e prestação de contas desses recursos. (MEC).

O Conselho escolar é um órgão que deve funcionar em harmonia com a comunidade escolar, é preciso que haja muita transparência nas reuniões que tratam do recebimento do recurso e clareza na execução, para que os conselheiros possam confiar e contribuir nos momentos das assembleias, dando sugestões e sendo multiplicadores das ações que beneficiam a instituição e contribuem para a melhoria do ensino e aprendizagem, fortalecimento e credibilidade da gestão.

\subsection{Caracterização da escola}

Esta pesquisa teve como objetivo, elaborar o perfil da Escola Municipal de Ensino Infantil e Fundamental Juracy Batista de Jesus, com dados referentes a endereço, quantidade de professores, equipe técnica e pedagógica, auxiliares, serviço de assistência ao estudante, número de turmas por série, espaço físico, o alunado que a escola atende e as principais dificuldades, além dos programas com os quais a escola é contemplada.

Este levantamento de dados é de fundamental importância para conhecer a realidade da escola, e diante dos fatos observados serão elencados os pontos positivos e negativos, além de identificar as necessidades fundamentais para uma educação de qualidade. Sabemos que a escola pública enfrenta muitas dificuldades, principalmente as escolas do campo, que aos poucos vêm conseguindo superar obstáculos que já foram bem maiores, mas através das lutas sociais têm conseguido algumas conquistas.

A Escola Municipal de Ensino Infantil e Fundamental Juracy Batista de Jesus está localizada no Assentamento Massangana I, Zona Rural Cruz do Espírito Santo, esta instituição tem como gestora a Senhora Maria do Socorro de Paiva.

Seu corpo docente é formado por 03 professores de nível superior e 05 de nível pedagógico. A mesma enfrenta uma dificuldade por não ter uma equipe técnica pedagógica da própria escola como: supervisor escolar, orientador educacional, psicólogo, assistente social. O acompanhamento pedagógico é realizado por uma equipe de supervisores da Secretaria de Educação. Das instituições auxiliares não conta com Conselho de Classe, nem grêmio estudantil. Conta também com o programa Saúde na Escola, que tem ido para realizar palestra e ensinar as maneiras corretas de escovação. 
A escola funciona nos três turnos: manhã, tarde e noite, sendo pela manhã $1^{\circ}, 2^{\circ}, 3^{\circ}$; no turno da tarde, pré-escolar, $4^{\circ}, 5^{\circ}$; já no horário noturno, EJA (Educação de Jovens e Adultos da $1^{\mathrm{a}}$ a $4^{\mathrm{a}}$ série. Estão matriculados 120 alunos, do Ensino infantil até o $5^{\mathrm{o}}$ ano de Ensino Fundamental, a escola é constituída pelos seguintes espaços físicos: 03 salas de aula e 03 banheiros inadequados. Faltam dependências importantes aos alunos e professores como: diretoria, sala de professores sala de leitura, biblioteca, refeitório, auditório, sala de supervisão e vídeo. Atende exclusivamente aos alunos do assentamento, do Ensino Infantil ao $5^{\circ}$ ano do ensino Fundamental, EJA alguns alunos residem nos lotes a certa distância da agrovila onde está localizada a escola, mas a prefeitura disponibiliza transporte para condução até a instituição de ensino. O nível socioeconômico e cultural da população é baixo, eles têm a base na agricultura familiar, mas até o momento boa parte dos assentados ainda não conseguiu se estabilizar com um investimento sustentável, muitos ainda necessitam trabalhar nas usinas para complementar a renda.

A principal dificuldade enfrentada pela escola, diz respeito ao abastecimento d'água, existe um poço artesiano, mas que devido à problemas técnicos não funcionam e a escola é abastecida por carro pipa. E o espaço físico ainda é inadequado para um bom funcionamento. A escola é atendida pelos seguintes programas do governo federal: PDDE BÁSICO, PDDE INTEGRADO, PDDE ESTRUTURA, PDDE QUALIDADE, MAIS EDUCAÇÃO, PDE por uma única vez em 2012.

Administrar os recursos de uma escola é fazer escolhas, ou seja, é tomar decisões coletivas. Na ausência de projeto comum, uma coletividade utiliza os recursos que tem, esforçando-se, sobretudo, para preservar certa equidade na repartição dos recursos. Por essa razão, não se coloca a serviço de um projeto que proponha prioridade, a administração descentralizada dos recursos pode, sem benefício visível, criar tensões difíceis de vivenciar, com sentimentos de arbitrariedade ou de injustiça pouco propícios à cooperação. (PERRENOUD, 2000 p. 102).

\section{RESULTADO E DISCUSSÃO}

Todos os dados foram conseguidos através de questionário aplicado com a diretora e presidente do conselho escolar, tais questionários tornaram-se objeto de estudos, sendo analisados e comentados sobre os dados pesquisados. Ambos informaram que o recurso recebido através do conselho escolar do FNDE não é suficiente para atender as necessidades da escola como abastecimento de d'água, adequação nos banheiros e cozinha, quadra de esporte, sala de professores, sala de atividades culturais, entre outros.

Informado também ao ser creditado o recurso na conta do conselho é realizada uma reunião com os conselheiros e comunidade escolar, para apresentar o valor do recurso, em 
seguida, discutimos as necessidades e escolhemos as prioridades, registramos em ata $\mathrm{e}$ elaboramos um Plano de Ação (Orçamento Democrático). As principais dificuldades que a escola enfrenta é a falta de água e na infraestrutura, ou seja, o prédio ainda não está adequado para atender uma educação de qualidade.

Os pais sempre são convidados para participar das reuniões, porque necessitamos ouvir a comunidade escolar para que ela tenha conhecimento dos recursos que entram no conselho da escola e juntos possa, tomar decisões democráticas. No tocante à prestação de conta dos recursos recebidos pelo Conselho Escolar, fazermos o seguinte procedimento; realizamos uma reunião do Conselho Escolar para apresentação da prestação de conta, comparamos o que foi programado no Plano de Ação e fazemos as justificativas quando necessário, por fim, elaboramos um parecer que após aprovação, registramos em ata e encaminhamos a prestação para Secretaria de Educação.

As informações coletadas através dos questionários aplicados aos conselheiros representantes dos professores, alunos, pais de aluno, funcionários, comunidade, foram objetos de estudos, sendo analisados e interpretados por meio de gráfico com a finalidade de atingir os objetivos desejados.

\section{Gráfico 01 - São convidados a participar das reuniões quando entra recurso na escola?}

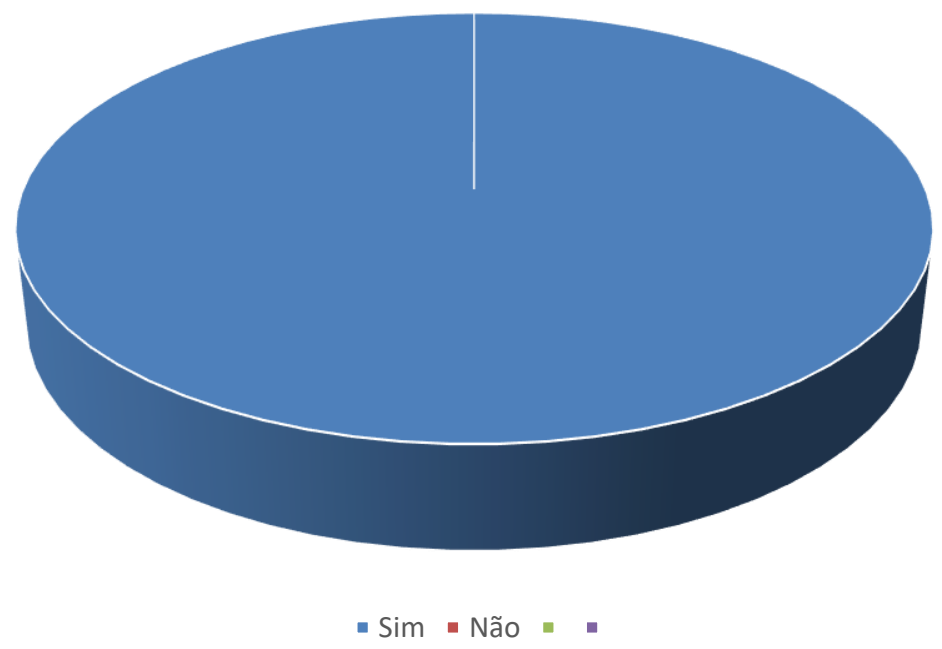

Fonte: Questionário de pesquisa

Cem por cento dos conselheiros entrevistados responderam sim. Este resultado aponta que os conselheiros são convidados a participar das reuniões sobre o destino dos recursos recebido pelo conselho escolar. Conforme as respostas analisadas nestes dados, a direção da escola e o presidente do conselho escolar, têm seguido as orientações do regimento do conselho escolar, e agindo de forma correta. Conforme o artigo 37 do estatuto do regimento interno das atribuições do presidente inciso $\mathrm{V}$, estimular a participação de todos os conselheiros em todas as reuniões do Conselho Escolar. 


\section{Gráfico 02 - Conhecimentos dos recursos que entra no Conselho Escolar?}

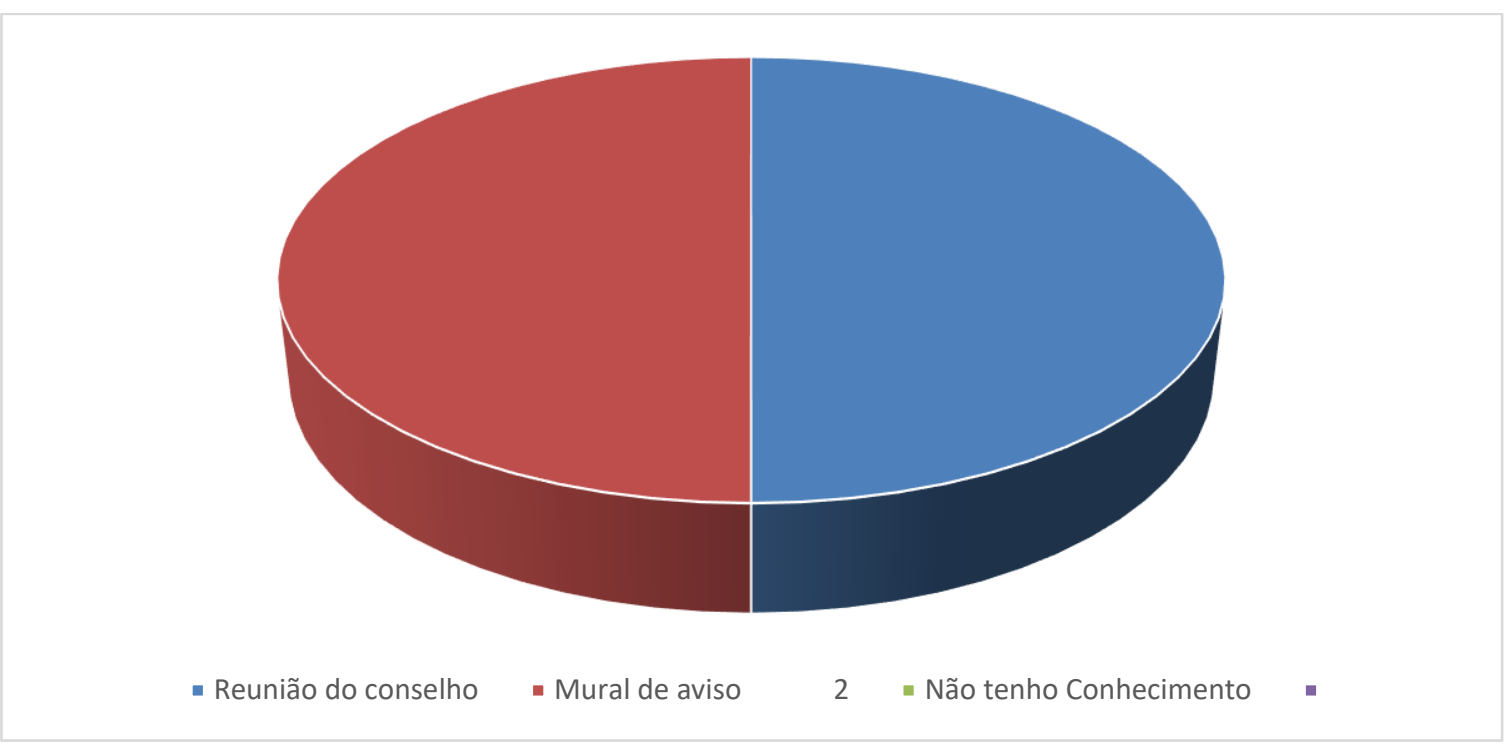

Fonte: Questionário de pesquisa

Cinquenta por cento dos conselheiros entrevistados opinaram que tomavam conhecimentos dos recursos recebidos pelo conselho escolar através de reuniões e cinquenta por cento responderam através de mural. De acordo com o artigo 39 do estatuto do regimento interno dos direitos dos conselheiros, inciso $\mathrm{V}$, solicitar em reunião do conselho, esclarecimento de qualquer natureza acerca das atividades da escola.

\section{Gráfico 03 - Procedimentos realizados pelo conselho para execução dos recursos}
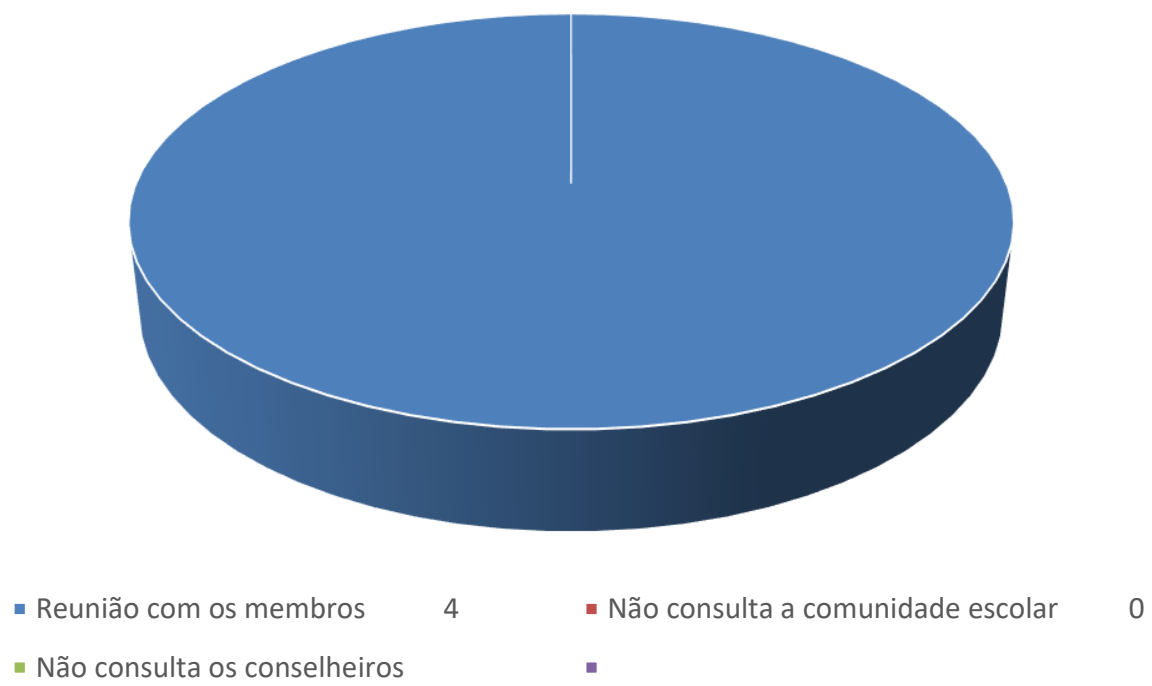

Fonte: Questionário de pesquisa 
Cem por cento dos conselheiros entrevistados afirmaram que é realizada uma reunião com membros do conselho para discutir como gastar o dinheiro (Orçamento Democrático). No artigo $5^{\circ}$ do estatuto do regimento interno diz:

\begin{abstract}
A gestão escolar um processo que rege o funcionamento da escola, compreendendo todas as decisões, planejamento, execução, acompanhamento e avaliações das questões administrativas e pedagógicas, efetivando o envolvimento da comunidade, no âmbito da unidade escolar, baseada na legislação em vigor e nas diretrizes pedagógicas administrativas fixadas pela Secretaria de Educação.
\end{abstract}

\title{
Gráfico 04 - Prestação de conta dos recursos do conselho escolar
}

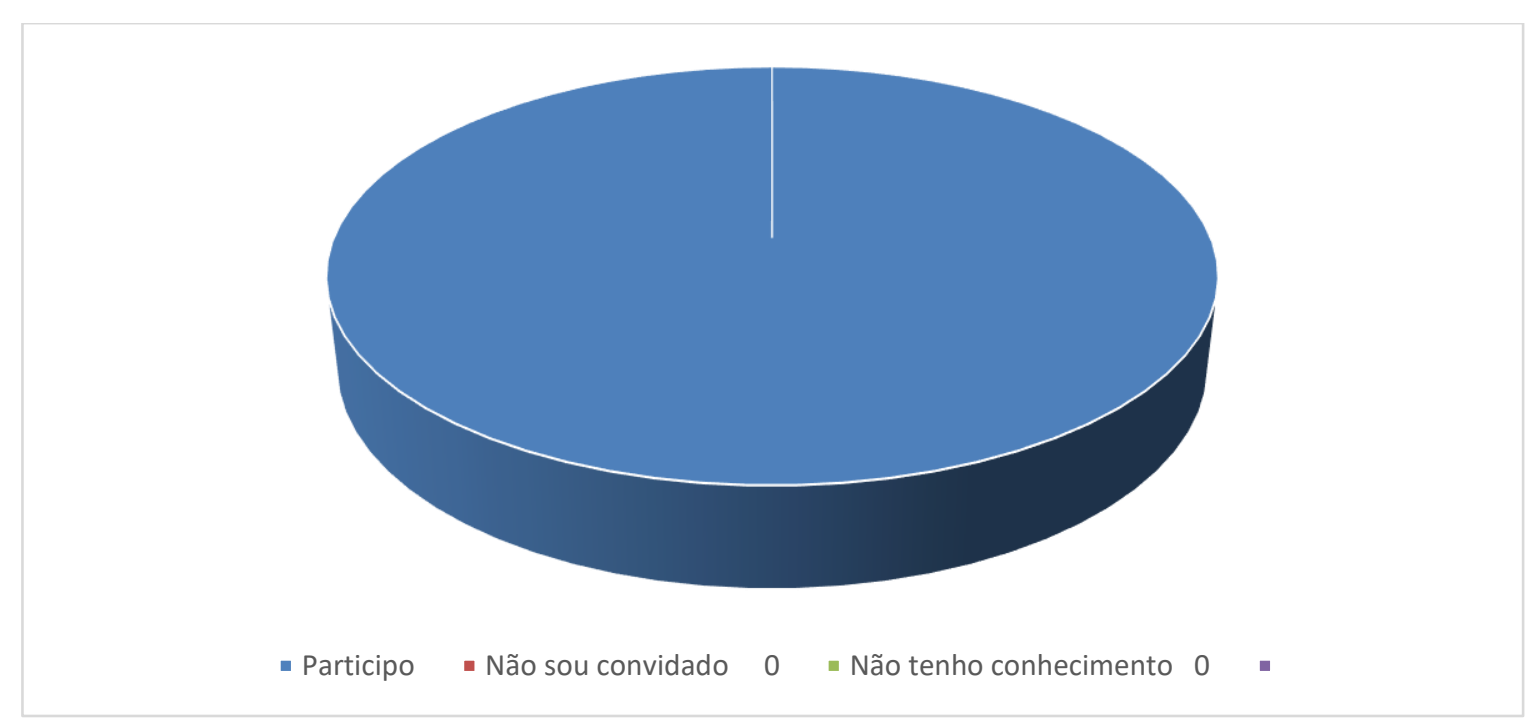

Fonte: Questionário de pesquisa

Cem por cento dos conselheiros entrevistados afirmaram que participam da reunião de prestação de conta dos recursos do conselho escolar. 


\section{Gráfico 05 - Avaliação da execução dos recursos pelo conselho da Escola}

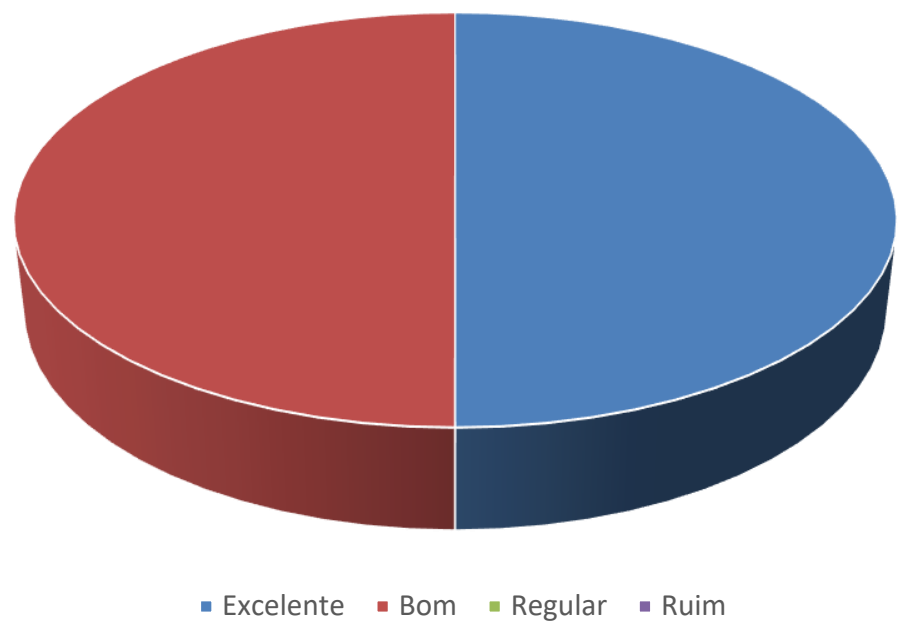

Fonte: Questionário de pesquisa

Cinquenta por cento dos conselheiros entrevistados, afirmaram que avaliam como excelente a execução dos recursos, e $50 \%$ avaliam como boa a execução dos recursos pelo conselho da escola. As informações coletadas através dos questionários aplicados ao diretor escolar e o presidente do conselho, foram objetos de estudos, sendo analisados e interpretados por meio de gráfico com a finalidade de atingir os objetivos desejados.

Gráfico 06 - Os recursos que são repassados pelo FNDE são suficientes para manutenção da escola?

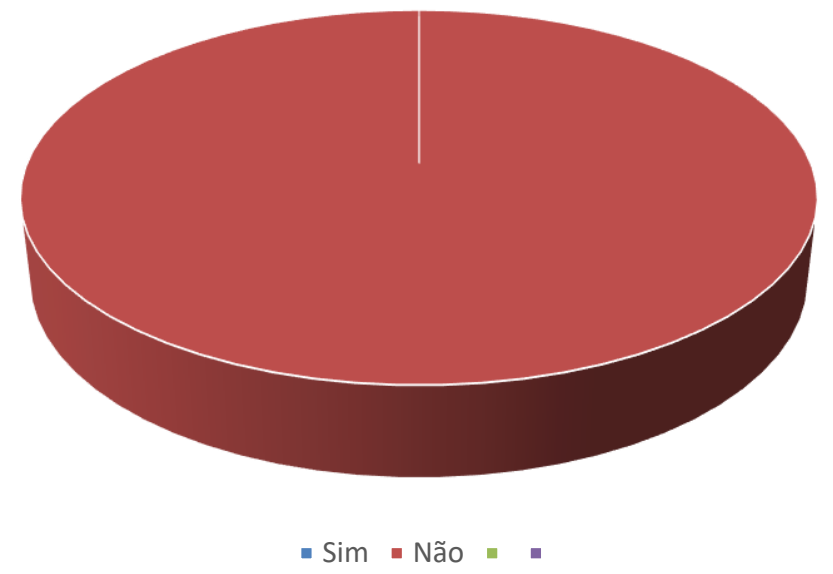

Fonte: Questionário de pesquisa 
Cem por cento das respostas foram justificando a carência da escola com a falta do abastecimento d'água, adequação em banheiro e cozinha, refeitório, quadra de esporte, sala de professores, sala de aula para atividades culturais, entre outros. Estas perguntas foram para o diretor escolar e o presidente do conselho.

Gráfico 07 - Os procedimentos que o conselho realiza após o recurso ser creditado na conta do Conselho Escolar

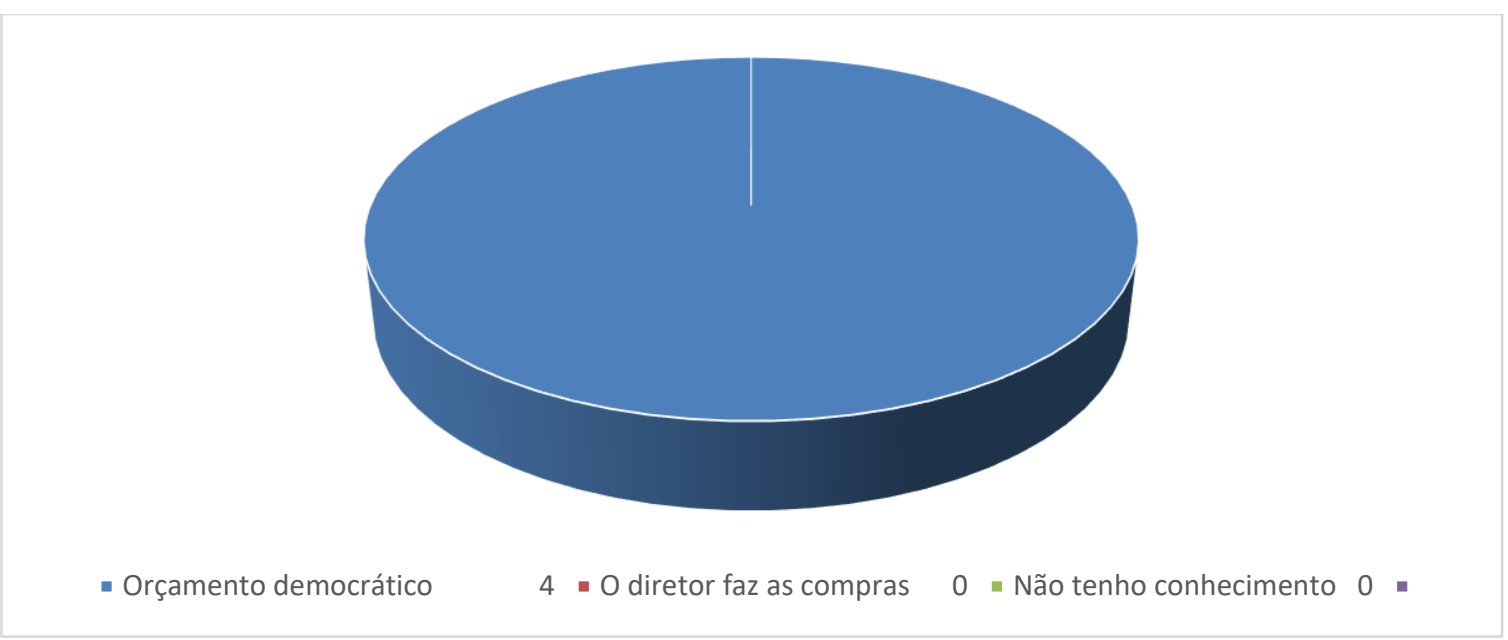

Fonte: Questionário de pesquisa

Em Cem por cento das respostas afirmaram que realizam uma reunião do Conselho para apresentar o valor do recurso, em seguida, discutimos as necessidades e escolhemos as prioridades, registramos em ata e elaboramos um Plano de Ação (Orçamento Democrático).

\section{Gráfico 08 - As principais dificuldades que a escola enfrenta com relação a recursos?}

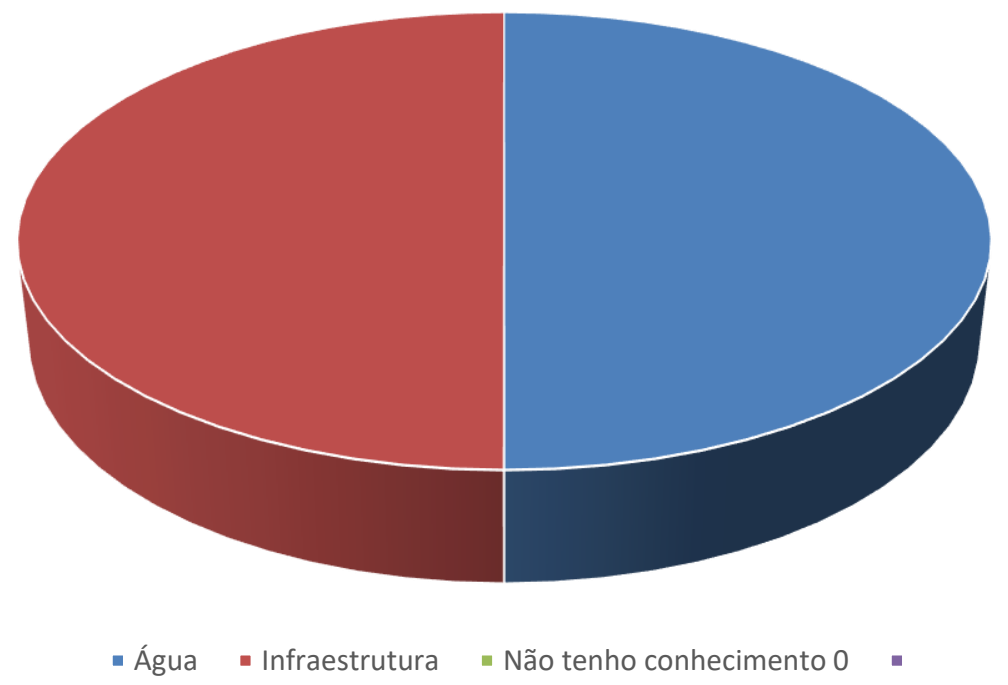

Fonte: Questionário de pesquisa 
Cinquenta por cento das respostas no tocante à água, apontam que a escola é abastecida por carro pipa, envida pela prefeitura municipal, e cinquenta por cento das respostas, no tocante à infraestrutura das escolas, vários cômodos que seriam essenciais à uma escola com biblioteca, refeitório, área de recreação, a instituição de ensino não tem, as oficinas do programa Mais Educação é realizada na sede da Associação dos moradores. Estas perguntas foram respondidas pelo diretor escolar e presidente do conselho.

\section{Gráfico 09 Como é realizada a prestação de conta dos recursos recebido pelo Conselho}

\section{Escolar?}

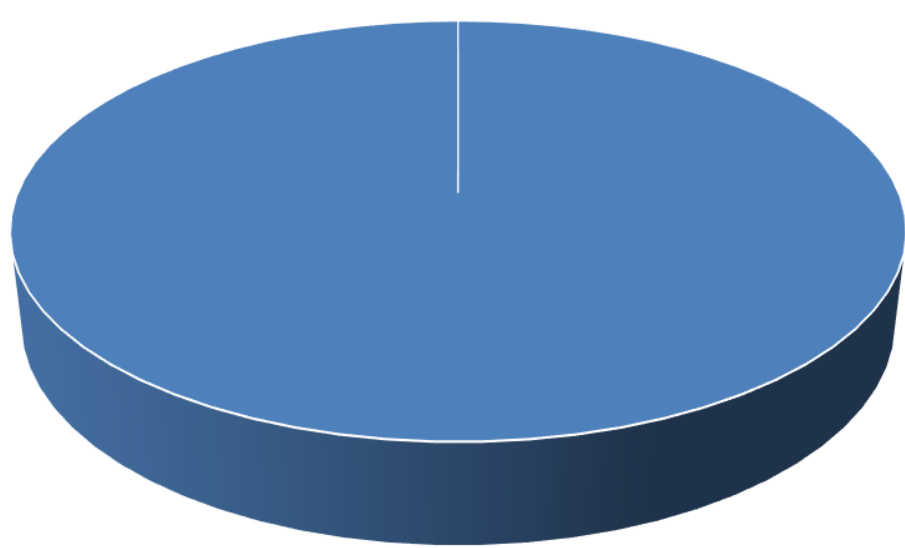

- Reunião de prestação de conta

- Não sou convidado

- Não tenho conhecimento

Fonte: Questionário de pesquisa

Por meio de Cem por cento das respostas afirmaram que realizam uma reunião do conselho Escolar para apresentação da prestação de conta, é feita uma análise do que foi programado no Plano de Ação, e então, é realizada uma justificativa quando for necessário, e elaborado um parecer que após aprovação pelo presente é registrado em ata e encaminhamos a prestação para Secretaria de Educação.

\section{CONSIDERAÇÕES FINAIS}

Ao concluir esta pesquisa pode-se constatar que a gestão do recurso da Escola Municipal de Ensino Infantil e Fundamental Juraci Batista de Jesus, segue os princípios da gestão democrática, pois conforme comprovam dados da pesquisa ao receber recursos, o conselho convoca a comunidade escolar e realiza o Orçamento Democrático Escolar e elabora seu plano de ação, a partir das orientações da Secretaria Municipal de Educação.

A pesquisa mostra que a gestão escolar está no caminho certo, visto que tem adotado em sua prática ações que contribui para um mecanismo de participação de diferentes atores sociais, 
que podem decidir em prol de melhoria para a comunidade escolar. Seu principal objetivo é aumentar a participação da comunidade com o conhecimento da gestão administrativa e financeira da escola pública e estimular o controle social para uma educação de boa qualidade.

Avaliamos também com base na pesquisa a participação dos conselheiros na prestação de conta, na qual é realizada uma comparação entre o plano de ação programado e as ações executadas, de modo que são realizadas justificativas das adequações financeiras sempre que necessário e elaborado um parecer em conformidade com a execução que é assinado pelos conselheiros e registrado em ata, que posteriormente é encaminhada como parte da documentação comprobatória para o setor de prestação de contas de Secretaria de Educação.

De acordo com a avaliação dos conselheiros representantes dos professores, alunos, dos funcionários, pais de alunos e comunidade, a gestão dos recursos pelo conselho escolar é apontada entre excelente e boa, mostrando que conforme os conselheiros os mesmos estão satisfeitos com a administração dos recursos recebidos pelo conselho escolar.

O mesmo propõe que através de uma assembleia sejam discutidas com a comunidade escolar as necessidades da escola e de acordo com o recurso sejam elencadas a prioridades, as mesmas sejam registradas em ata e elaborado um plano de ação que contemple as razões das prioridades e após a elaboração do plano apresentar a Secretaria de Educação que após uma avaliação é autorizada para realização de pesquisa e execução das compras.

Estes procedimentos adotados pela gestão e acompanhados pela Secretaria de Educação são muito louváveis, afinal de contas, percebemos que durante o período da pesquisa a escola realizou o seu orçamento democrático, elaborou o plano de ação e encaminhou a Secretaria de Educação.

Conforme observamos mesmo com as dificuldades que as escolas do campo enfrentam nos últimos anos, devido à crise que assola o país o município de Cruz do Espírito Santo - PB, através de seus gestores tem tido uma atenção especial com o pouco recurso que é disponibilizado pelo FNDE, para que seja executado de forma planejada com o objetivo de alcançar o que a comunidade escolar apresenta como a maior necessidade.

Conforme a informação constatada, fica evidente a importância do orçamento democrático porquê de acordo com a pesquisa a comunidade escolar participou, mas é preciso melhores esclarecimentos e acompanhamento da gestão dos conselhos escolares, para evitar que a escola tenha suas prestações de conta reprovadas e, consequentemente, a suspensão de recurso do FNDE.

Mediante os dados analisados percebemos que a referida escola realiza reuniões com o conselho para definir necessidades e prioridades da escola na compra de materiais e execução de serviço como o recurso do PDDE, no entanto, não existia uma lei que normalizasse tal ação no município, por essa razão será sugerida ao poder público municipal uma lei que legalize o orçamento democrático das escolas municipais. 


\section{REFERÊNCIAS}

ARROYO, Miguel: FERNANDES, Bernardo M. A Educação Básica e o Movimento Social do Campo. Vol. 2. Brasília, DF: articulação nacional por uma educação básica do campo, 1999.

BRASIL. Congresso Nacional. LDB - Lei de Diretrizes e Bases da Educação Nacional, $N^{\circ}$ 9394/96.

BRASIL. Ministério da Educação. Conselho Nacional de Educação. Diretrizes Operacionais para Educação Básica nas Escolas do campo. Brasília - DF: 2001.

BATISTA, M. S. X. Educação do Campo; um Paradigma classista de educação. In. Dias, Adelaide Alves; MACHADO, Charlinton J. Santos; Nunes, M. Lúcia da Silva. (org.) Educação, direitos humanos e inclusão social: Currículo, formação docente e diversidades socioculturais. 1 ed. João Pessoa /Pb: Editora Universitária UEFPB, 2009, v. 1 p. $207-225$

, Maria do Socorro Xavier; VICENTE, Darfina. Socorro S. Educação do

Campo e currículo: fortalecendo a identidade camponesa.

CALDART, Roseli Salete. Elemento para construção do Projeto Político

Pedagógico da Educação do campo. In: MOLINA, Monica Castagna e JESUS, Sonia Meire dos Santos Azevedo de. Contribuições para Construção de um Projeto de

Educação do Campo. Brasília, DF: Coleção por uma Educação do Campo, nº 05, 2005 p.19.

FREIRE. Paulo. Conscientização: teoria e prática da libertação: uma introdução ao pensamento Paulo Freire; [tradução de Kátia de Mello e Silva; revisão técnica de Benedito Eliseu Leite Cintra]. - São Paulo: Cortez \& Morais, 1979.

GADOTTI, Moacir. CONCEPÇÃO DIALÉTICA DA EDUCAÇÃO: um estudo introdutório. 12 ed. ver. SP. Cortez. 2001.

http://paraiba.pb.gov.br/sape-recebe-seminario-regional-de-educacao-no-campo-nestasemana/ Acessado no dia 12 de nov. 2015.

HENRIQUES, Ricardo. Et al. Educação do campo: diferenças mudando Paradigmas. Brasília: MEC/SECADI, 2007.

MEC. Lei de Diretrizes e Bases da Educação. Brasília, 1996.

MEC. Conselho Escolar na democratização da escola

PERRENOUD, Philippe. 10 Novas competências para ensinar/ trad. Patrícia Chittoni Ramos, Porto Alegre: Artes Médica Sul, 2000. 
SAVIANI, Demerval. Educação: Do senso comum à consciência filosófica. 11 ed. Campinas, SP: Autores Associados, 1993.

VEIGA, Ilma P. A. Projeto político-pedagógico da escola: uma construção coletiva. In:

P.A. (org.). Projeto político-pedagógico da escola: uma construção possível. Campinas: Papirus, 1996.

Recebido em: 05/01/2022

Aprovado em: 08/02/2022

Publicado em: 12/02/2022 